\title{
Carrier Optimization Using CAD Software and Biologically Inspired Algorithms
}

\author{
Marija Mojsilović ${ }^{*}$, Ivana Terzić ${ }^{2}$, Snežana Gavrilović ${ }^{3}$, Goran Miodragović ${ }^{4}$
} Academy of Vocational Studies Šumadija - section Trstenik

This paper presents a comparative analysis of the application of biologically inspired algorithms and methodologies in CAD software packages, for determining the optimal profile values in carriers with two independent variables.

As an example of a biologically inspired algorithm to solve this optimization problem, the scroll algorithm was applied, while the SolidWorks software package was used as an example of CAD.

Keywords: metaheuristics, nonlinear optimization, biologically inspired algorithms, firefly algorithm, CAE.

\section{INTRODUCTION}

When it comes to the calculation and optimization of machine constructions, the application of the finite element method is unthinkable. As effective as this method is, specialized software, based on this method, is in most cases intended for specialists, not conventional engineers. Fortunately, modern CAD / CAM systems have built-in, user-oriented, modules for calculation and optimization of structures.

At the end of the XX and the beginning of the XXI century, biologically inspired methods appeared, which efficiently solve complex optimization problems.

The advantage of these algorithms is that they can be applied to a large number of optimization problems, as well as their adaptability to the optimization problem. Also, these methods do not require experience in determining the initial values of variables, because it is possible to set a wide range for the initial values of variables.

This paper presents the optimization of machine constructions using the Simulation module, SolidWorks software package, as well as the optimization using the roll algorithm (Firefly Algorithm - FA). The original algorithm without any modifications was used.

\section{FORMING A CARRIER MODEL}

Solving the problem of stability of real girders often requires significant simplifications that are necessary for analytical assessment of the problem, in order to verify a detailed mathematical model.

In the example given in the literature [1], the problem of carriers with two variables will be considered. For this example, it is required that the deflection of the free end of the bracket does not exceed the allowable value, with the contradictory requirement of minimizing the weight (mass) of the carrier.

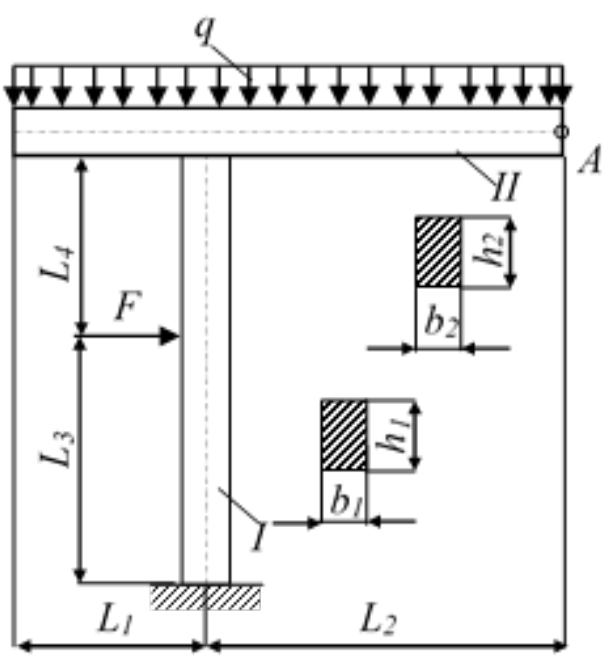

Figure 1.Optimization model of a carrier with two variables

\subsection{Carrier model with two variables}

A complex support with two mutually perpendicular beams of rectangular cross-section is observed here, [1]. The idea is to get a support of as small a volume as possible (minimum mass), i.e. the optimal values of the profile height $\mathrm{h}_{1}\left(=\mathrm{x}_{1}\right)$ and $\mathrm{h}_{2}\left(=\mathrm{x}_{2}\right)$, Figure 1 .

This problem was determined by two independent project variables. In this case, too, the problem is solved under the condition that the deflection of the free end, at point $\mathrm{A}\left(=\mathrm{u}_{\mathrm{A}}\right)$, must not exceed the set value. The girder is loaded with horizontal force (F), co and continuous load (q), Figure 1.

The known values of the model from Figure 1 are:

$F=20 \cdot 10^{3}[\mathrm{~N}]$,

$q=2 \cdot 10^{3}[\mathrm{~N} / \mathrm{m}]$;

Jung modulus of elasticity:

$\mathrm{E}=20 \cdot 10^{9}[\mathrm{~Pa}]$ 
Main moments of profile inertia:

$I_{1}=1.666 \overline{6} \cdot 10^{-2} \cdot h_{1}^{3}\left[m^{4}\right]$

$I_{2}=1.666 \overline{6} \cdot 10^{-2} \cdot h_{2}^{3}\left[m^{4}\right]$

Lengths: $\mathrm{L}_{1}=2[\mathrm{~m}] ; \mathrm{L}_{2}=\mathrm{L}_{3}=3[\mathrm{~m}] ; \mathrm{L}_{4}=2[\mathrm{~m}]$

Profile widths: $b_{1}=0.2[\mathrm{~m}] ; b_{2}=0.2[\mathrm{~m}]$;

The mathematical model of this optimization problem is given by equations.

Minimization:

$\mathrm{F}(\mathrm{X})=\mathrm{x}_{1}+1.2 \cdot \mathrm{x}_{2},\left[\mathrm{~m}^{3}\right]$, under restriction:

$\mathrm{u}_{\mathrm{A}}(\mathrm{X})=1.7999 \cdot 10^{-3} / \mathrm{x}_{1}{ }^{3}+1.7999 \cdot 10^{-4} / \mathrm{x}_{2}{ }^{3} \leq 0.02[\mathrm{~m}]$,

where is $\mathrm{X}=\left(\mathrm{x}_{1}, \mathrm{X}_{2}\right)$.

The constraints of the project variable, $\mathrm{x}_{1}$ and $\mathrm{x}_{2}$ are given by the equation:

$$
0.1 \leq \mathrm{x}_{1} \leq 0.8 ; 0.1 \leq \mathrm{x}_{2} \leq 0.8
$$

\section{CARRIER OPTIMIZATION IN SOLIDWORKS}

\subsection{Software package SolidWorks}

SolidWorks Simulation is a software module, within the SolidWorks software package, which is used to analyse the construction model based on finite element methods. In this program module, the following can be performed: static and dynamic analysis of the structure (behaviour of the CAD model of the structure due to static and dynamic taxation), frequency analysis (analysis of structure oscillation), free fall analysis, structural reinforcement analysis. Also, this tool enables thermal analysis, i.e. analysis of heat radiation, heat conduction and heat resistance through the model of CAD model construction.

3.2. Optimization procedure in the SolidWorks software package

The optimization process, in SolidWorks, begins with the formation of a 3D model. In order to make a 3D model, it is first necessary to form 2D sketches, by which, with one of the 3D operations (extrude, revolve, swept, loft), the desired 3D model is obtained, Figure 2, [6]. The modelling is started by selecting the desired plane, in which the sketch is formed, which needs to be dimensioned, i.e. completely defined.

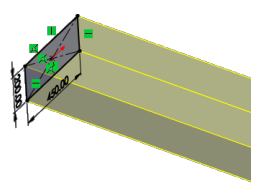

a)

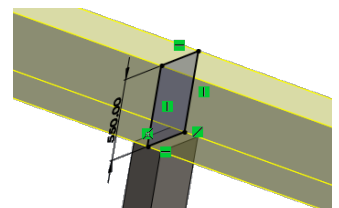

b)
Figure 2. Sketch and formation of a $3 D$ model for an example of a beam with two variables (a) vertical beam, (b) horizontal beam
In Figure 2, the rectangular profiles of which the given girders are composed are defined. It can be noticed that they are all marked in black, which means that they are completely defined. Although the subject of optimization is to find the profile height, at the time of modelling some initial, initial value must be defined in order to start the optimization process, finding the optimal profile height $\left(\mathrm{h}_{1}\right.$ and $\left.\mathrm{h}_{2}\right)$, which actually gives the lowest mass, that is, the weight of the profile, where the total deflection at point $\mathrm{A}, \mathrm{u}_{\mathrm{A}}$, must not exceed the set value.

\subsection{Formation of models for calculation of deflection and strength of carrier}

After forming the model, the first step is to define the material of which the carrier is made. The material used in this simulation is AISI 1035 Steel (SS), which according to its characteristics, Jung's modulus of elasticity and strength of the material, corresponds as given in the examples.

In these examples, the connections are not defined because it is a welded joint and as such it can be considered that the carrier is compact. So, it is necessary to define the supports, [4]. It is a clamping of the bracket at one end and this is defined in the External Loads menu.

When the supports are defined, it is necessary to define the loads as well. In Figure 3, which show the definition of the model, it can be seen that in certain places there is a defined point (Point 1). This point is in fact the point of attack of the force acting on the carrier.

The External Loads submenu is used to define this external load. By running this subroutine and selecting the Force option, all the necessary parameters are defined, Figure 3, the attack point selection and the force intensity, [4].

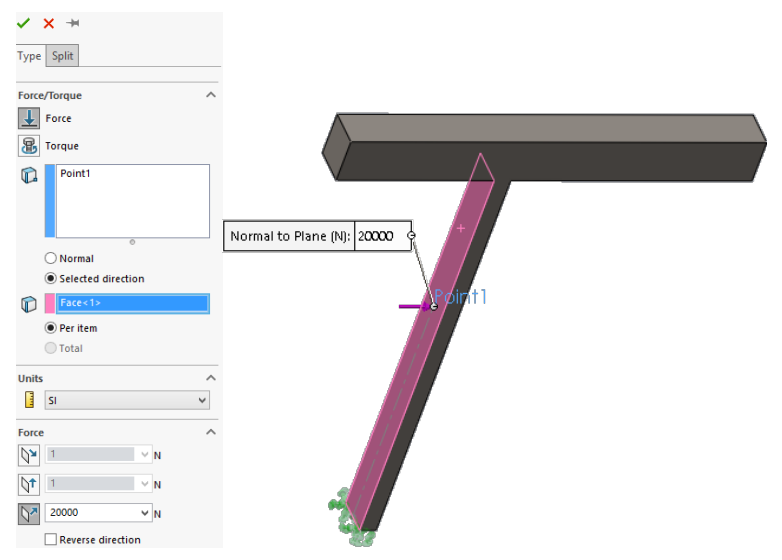

Figure 3. Defining force (point of attack and intensity)

The continuous load acting on the horizontal part of the girder is defined in a similar way, Figure 4, [4]. Only in this case the surface is chosen as the place of action of the load. 


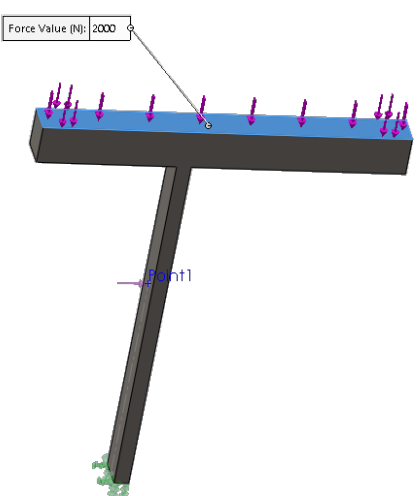

Figure 4. Defining a continuous load

When the definition of the simulation model is completed, a simulation is started, the aim of which is to obtain the initial values for deflection and stresses, Figure 5 .

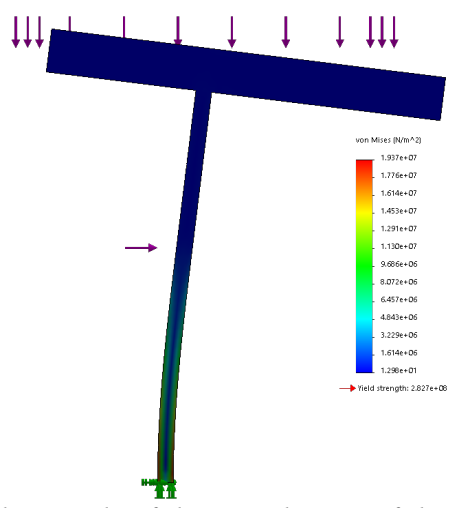

Figure 5. The result of the simulation of the carrier with two variables - stress diagram

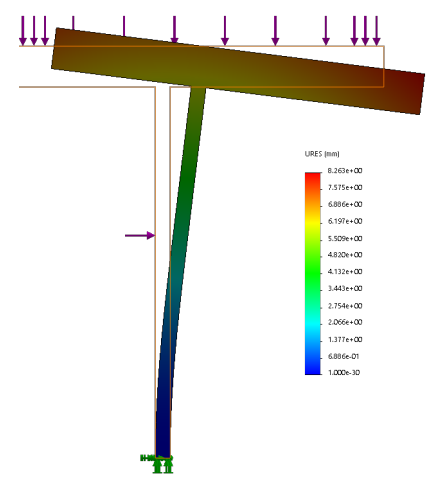

Figure 6. The result of the simulation of the carrier with two variables - deflection diagram

From Figure 6, it can be seen that the stresses in the structure are below the allowable value, while the maximum, total deflection, at point $\mathrm{A}, \mathrm{u}_{\mathrm{A}}=8.263 \mathrm{~mm}$. The next step is to define an optimization model.

\subsection{Forming a model for carrier optimization}

The optimization model starts with the launch of the Design Study subroutine, within the Simulation module, Figure 7, [4].

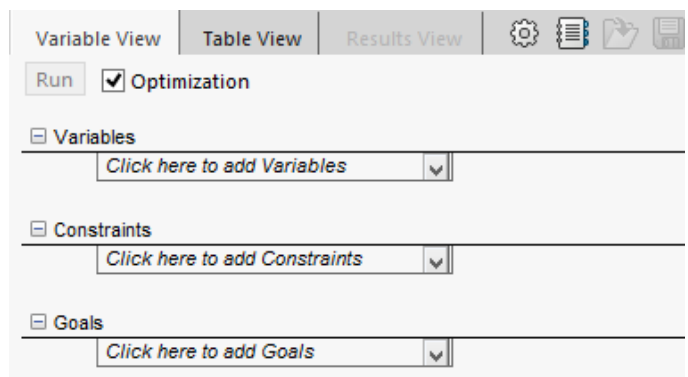

Figure 7. Defining optimization parameters in the Design Study subroutine

The first step is to select the design variables and set the boundaries within which the best solution is sought, Variables, Figure 7. To define the variables, the dimensions used to define the profiles used to form the girder model will be used, Figure 8 .

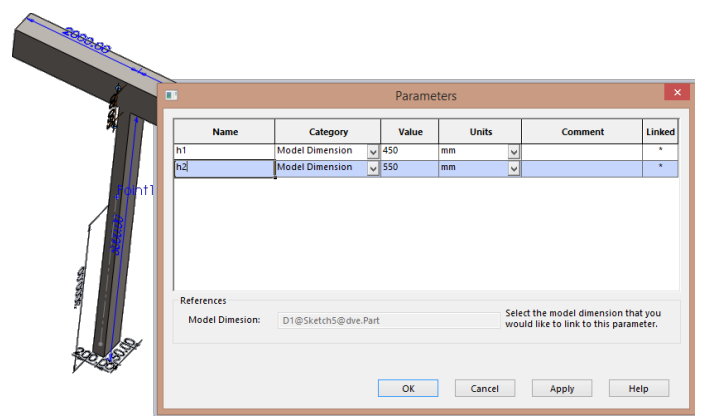

Figure 8. Defining project variables

When the variables are selected, it is necessary to define the range in which the solution of the equation is sought, Figure 9. The minimum and maximum value is set, as well as the step by which the scenarios for the optimization process are formed.

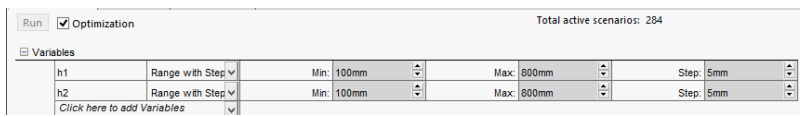

Figure 9. Scenario formation for the optimization process

Optimization remains to be done. The duration of the simulation depends primarily on the complexity of the model, as well as on the number of scenarios. After the simulation is completed, the result is obtained, as shown in Figure 10. As can be seen from Figure 10, the optimal solution is in scenario 10 .

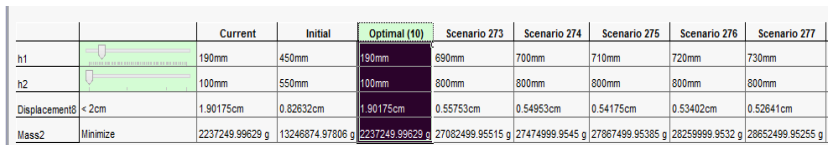

Figure 10. The result of the simulation of a carrier with two variables

The results of the simulation load model are given in Figure 11. As can be seen, the deflection limit is within the limits $(<2 \mathrm{~cm})$, while the stress is still within the allowable stress limits.

The following chapter provides an overview of the results in relation to the results obtained by the finite element method presented in [1]. 

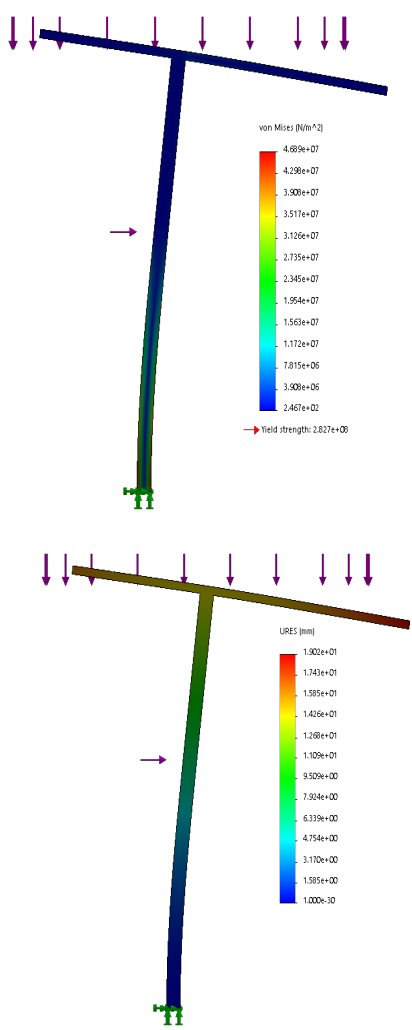

Figure 11. The result of the load simulation of the girder with the found solution.

\subsection{Carrier optimization results}

Before the comparative results are presented, Figure 12 shows the deflection of the girder, based on the obtained optimization results.

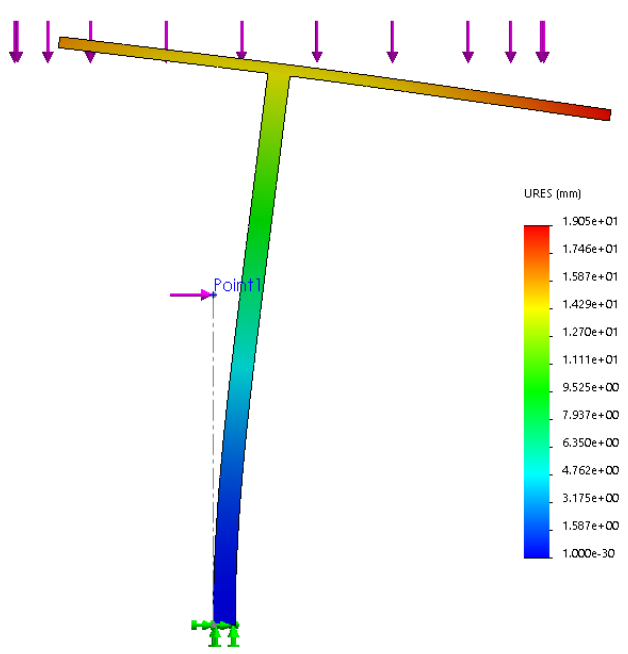

Figure 12. Deflection of the carrier, $u_{A}=1.901751 \mathrm{~cm}$, with two independent variables, example Figure 1., at $h_{1}=$ $190 \mathrm{~mm}$ and $h_{2}=100 \mathrm{~mm}$.

Table 1 provides a comparative overview of the results obtained with the results obtained using the First Order Method (FOM) and the Subproblem Approximation Method [1] and using SolidWorks.
Table 1. Comparative results for optimization of onedimensional support, Figure 1.

\begin{tabular}{|c|c|c|c|}
\hline & $\begin{array}{c}\text { First order } \\
\text { Method (FOM) } \\
{[4]}\end{array}$ & $\begin{array}{c}\text { Subproblem } \\
\text { Approximation } \\
\text { Method [4] }\end{array}$ & SolidWorks \\
\hline $\mathrm{x}_{1}[m]$ & 0.22558 & 0.22556 & $\mathbf{0 . 1}$ \\
\hline $\mathrm{u}_{\mathrm{A}}[\mathrm{m}]$ & 0.0099961 & 0.0099998 & $\mathbf{0 . 0 0 7 2 1 1 1 *}$ \\
\hline $\begin{array}{c}\text { The best value } \\
{\left[m^{3}\right]}\end{array}$ & 0.13535 & 0.13533 & $\mathbf{0 . 0 6}$ \\
\hline $\begin{array}{c}\text { The mean value } \\
\text { The worst value }\end{array}$ & N.A & N.A & N.A \\
\hline S.D. & N.A & N.A & N.A \\
\hline
\end{tabular}

From Table 1, it can be seen that the best solution (minimum volume - mass) of the girder is obtained by the procedure in Solid Works, while satisfying the deflection limit at point $A$, and $A<2$. First Order Method (FOM) and Subproblem Approximation Method give slightly worse results. However, if the value of the variable $x_{1}=0.1 \mathrm{~m}$ is included in the equation, $0.11575 \mathrm{~m}(>0.1 \mathrm{~m})$ will be obtained for the deflection $\left(u_{A}\right)$, and this value does not satisfy the set limit. This suggests that the methodology of performing optimization in Solid Works does not give good results.

Table 2, gives a comparative presentation of the obtained results with the results, obtained using the graphical method and ANSYS / Design Optimization [1] and using SolidWorks. From this table it can be seen that the result obtained by the optimization method in SolidWorks is the best, however, as with the twodimensional carrier, the constraint given by the equation with the values of variables $x_{1}$ and $x_{2}$ is not satisfied, because for these values for $u_{A}$ is obtained 0.454 from $0.02 \mathrm{~m}$.

Table 2. Comparative results for two-dimensional support optimization

\begin{tabular}{|c|c|c|c|}
\hline & $\begin{array}{c}\text { Graphical } \\
\text { Method [4] }\end{array}$ & $\begin{array}{l}\text { ANSYS/Design } \\
\text { Optimization [4] }\end{array}$ & SolidWorks \\
\hline $\mathrm{x}_{1}[\mathrm{~m}]$ & 0.30674 & 0.30751 & 0.190 \\
\hline $\mathrm{x}_{2}[\mathrm{~m}]$ & 0.51282 & 0.51291 & 0.100 \\
\hline $\mathrm{u}_{\mathrm{A}}[m]$ & 0.02 & 0.019972 & $0.0190175^{*}$ \\
\hline $\begin{array}{l}\text { The best value } \\
\qquad\left[\mathrm{m}^{3}\right]\end{array}$ & 0.92215 & 0.923 & 0.29 \\
\hline The mean value & N.A & N.A & N.A \\
\hline The worst value & N.A & N.A & N.A \\
\hline S.D. & N.A & N.A & N.A \\
\hline
\end{tabular}

\section{BIOLOGICALLY INSPIRED OPTIMIZATION OF ALGORITHMS}

Biologically inspired optimization of algorithms are inspired by phenomena in nature (biologically algorithms) belong to a group of so-called metaheuristic optimization methods. These algorithms simulate natural processes and 
systems when performing the process of searching the space for possible solutions, [6]. A special class of algorithms, among these algorithms, that has been developed, is inspired by the intelligence of concepts (swarm intelligence - SI). Examples of these algorithms are: ant colony optimization (ACO) algorithm, particle swarm optimization (PSO) algorithm, cuckoo search (CS) algorithm, bat algorithm (BA), firefly algorithm (firefly algorithm - FA), krill herd algorithm (KH), grey wolf algorithm (Grey Wolf Optimizer). In the continuation of the paper, an overview and application of the firefly algorithm is given, on the optimization of the carrier given in the previous chapters.

\subsection{Firefly algorithm (FA)} scroll algorithm (FA) as a biologically inspired optimization algorithm. As its name suggests, this algorithm is based on the behaviour of the scrolls in nature. To form the firefly algorithm (FA), some characteristics of the flickering light of the firefly's are simplified (idealized). These simplifications can be represented by three idealized rules, [2] [3]: all coils are attracted to each other regardless of gender, i.e. they are considered to be unisexual;

- the intensity of attraction is proportional to the brightness of the flicker, so that the coil, with less bright light, moves in the direction of the firefly which flickers with stronger intensity. The attractiveness and intensity of light flicker decreases as the distance between the lights increases. If there is no stronger intensity of light flicker near one of the scrolls, it moves at random;

- The intensity of the flickering light of the firefly is determined depending on the space defined by the target function.

The pseudocode, the scroll algorithm (FA), is given in $\mathrm{A}-2$, [2] [3].

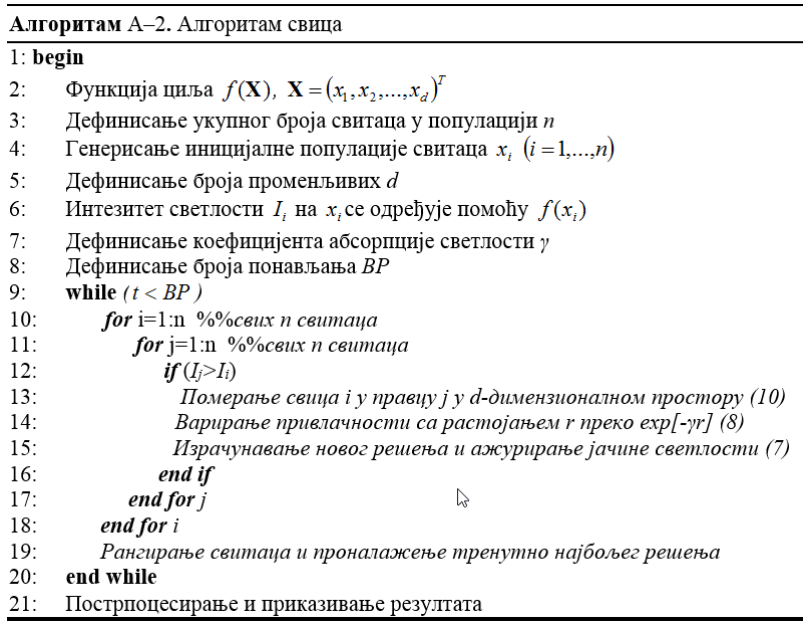

The intensity of the light flickers $I$, will change inversely proportional to the square of the distance from the source, where the intensity of the light flicker is the source. For a known medium with, constant coefficient of light absorption, $\gamma$, the intensity of light flicker, $I$, changes with the change of distance, $r$.

$$
I(r)=I_{0} e^{-r r}
$$
flicker.

In the equation is the initial intensity of light

It was previously stated that the attractiveness of the coils is proportional to the intensity of the light flicker. Considering this fact, the attractiveness of the coil, $\beta$, can be defined by the equation.

$$
\beta(r)=\beta_{0} e^{-r^{2}} \text { and } \beta=\frac{\beta_{0}}{1+r^{2}}
$$

where $\beta_{0}$ is the attraction at $r=0$.

The distance between two coils, i-th and $\mathrm{j}$-th, and, respectively, represents the distance in Cartesian coordinates, equation.

$$
r_{i j}=\left\|x_{i}-x_{j}\right\|=\sqrt{\sum_{k=1}^{d}\left(x_{i, k}-x_{j, k}\right)^{2}}
$$

where $\mathrm{x}_{\mathrm{i}}, \mathrm{k}$ is the $\mathrm{k}$-th component of the spatial coordinate of the $\mathrm{x}_{\mathrm{i}}$-th coil. In 2-D space, it is:

$$
r_{i j}=\sqrt{\left(x_{i}-x_{j}\right)^{2}+\left(y_{i}-y_{j}\right)^{2}}
$$

4.2. Results of beam optimization using standard firefly algorithm

For the example of the carrier, given in Figure 1, the parameters of the algorithm are as follows:

- number of firefly 55 ,

- the number of iterations is 1000 .

Table 3 shows the results of the carrier optimization, while Figure 13 shows the generation of results during the iterative process of finding the optimal solution.

Table 3. Results of carrier optimization using the fireflyFA algorithm.

\begin{tabular}{|c|c|}
\hline & $\begin{array}{c}\text { Carrier with two } \\
\text { variables }\end{array}$ \\
\hline $\mathrm{x}_{1}[\mathrm{~m}]$ & 0.2459114161 \\
\hline $\mathrm{x}_{2}[\mathrm{~m}]$ & 0.1342735773 \\
\hline $\mathrm{x}_{3}[\mathrm{~m}]$ & 1.98142696 \\
\hline $\mathrm{u}_{\mathrm{A}}[\mathrm{m}]$ & $\mathbf{0 . 4 0 7 1 5 6 3 5 3 1}$ \\
\hline $\begin{array}{c}\text { The best value } \\
{\left[\mathrm{m}^{3}\right]}\end{array}$ & 0.41081 \\
\hline $\begin{array}{c}\text { The mean value } \\
\text { The worst value }\end{array}$ & 0.4332139718 \\
\hline S.D. & 0.0071214785 \\
\hline
\end{tabular}




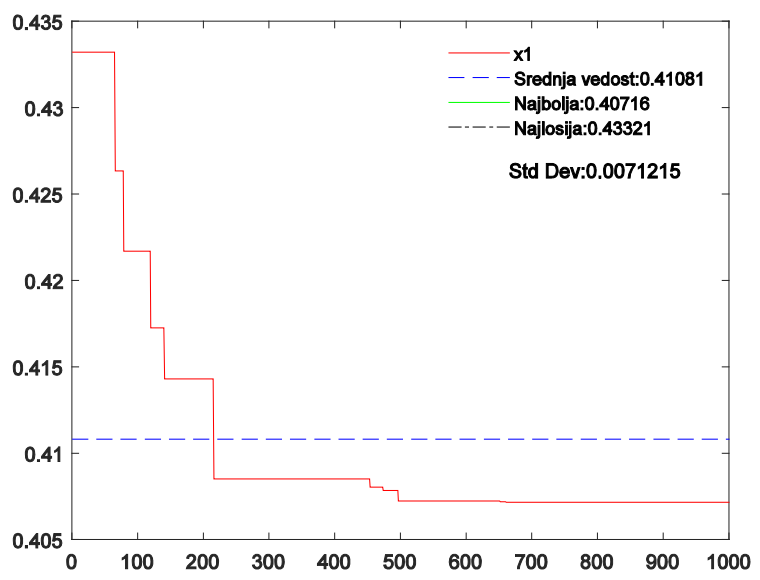

Figure 13. Best, mean, worst value of the target function and standard deviation of the two-dimensional carrier using the FA algorithm

In Figure 13, with a two-dimensional carrier, the solutions quickly converge to the best solution after approximately 250 iterations.

The results shown in Table 3 show that the allowable deflection, $\mathrm{uA}$, is within the limits and that the standard deviation is low.

\section{COMPARATIVE RESULTS OF CARRIER OPTIMIZATION}

In this chapter, comparative results of optimization by First Order Method (FOM), ie Graphic method, Subproblem Approximation Method, SolidWorks and optimization by firefly algorithm will be presented. The results of the examples are shown in Table 4.

As it has been shown in Chapter 3 that the results obtained in SolidWorks * do not meet the set limits, the reliability and accuracy of the results obtained in this way can be questioned. For this reason, the results obtained by this optimization will not be considered.

From Table 4, it can be seen that the best result was obtained using the firefly algorithm.

Table 4. Comparative results for two-dimensional girder optimization, Figure 1.

\begin{tabular}{|c|c|c|c|c|c|}
\hline & $\begin{array}{c}\text { Graphical } \\
\text { method }\end{array}$ & $\begin{array}{c}\text { ANSYS/ } \\
\text { Design } \\
\text { Optimization }\end{array}$ & SolidWorks* & $\begin{array}{c}\text { BA } \\
\text { algorithm }\end{array}$ & FA algorithm \\
\hline $\mathrm{x}_{1}[\mathrm{~m}]$ & 0.30674 & 0.30751 & 0.190 & 0.24609 & 0.2459114161 \\
\hline $\mathrm{x}_{2}[\mathrm{~m}]$ & 0.51282 & 0.51291 & 0.100 & 0.13432 & 0.1342735773 \\
\hline $\mathrm{u}_{\mathrm{A}}[\mathrm{m}]$ & 0.02 & 0.019972 & 0.0190175 & 0.02 & 0.0198142696 \\
\hline $\begin{array}{c}\text { The best value } \\
{\left[\mathrm{m}^{3}\right]}\end{array}$ & 0.92215 & 0.923 & 0.29 & 0.40727131 & 0.4071563531 \\
\hline $\begin{array}{c}\text { The mean } \\
\text { value }\end{array}$ & N.A & N.A & N.A & 0.40794 & 0.41081 \\
\hline $\begin{array}{c}\text { The worst } \\
\text { value }\end{array}$ & N.A & N.A & N.A & 0.47721 & 0.4332139718 \\
\hline S.D. & N.A & N.A & N.A & 0.005384 & 0.0071214785 \\
\hline
\end{tabular}

\section{CONCLUSION}

This paper aimed to perform a comparative analysis of different optimization methods on the example of a carrier with two variables. Examples are models from the known literature [1]. The methods that are compared are based on engineering optimization: First Order Method (FOM), Subproblem Approximation Method and SolidWorks, for two-dimensional carrier optimization, ie Graphic Method and ANSYS / Design Optimization, with optimization algorithms - FA.

The optimization process, using SolidWorks, is very simple and intuitive, ie user-oriented. After the formation of the 3D model, it is approached to define the supports and the load that will act on the support. After that, the load simulation is started and as a result of the simulation, the deflection and stress diagrams are obtained. After that, the definition of the parameters to be optimized, the constraints and the functions of the target are started. The disadvantage of this procedure is that the software creates scenarios depending on the set limit values of the variable, which is optimized and the step of changing the value. This can lead to a large number of steps, where there is a danger of "skipping" the optimal value. The procedure itself takes quite a long time and requires full utilization of computer resources. In addition, it has been shown that the resulting gain, when the values of the obtained variables are inserted into the equation far exceeds the set limit, which leads to doubts about the correctness of the optimization process with SolidWorks software. Therefore, the results obtained by this optimization were not considered below.

The firefly algorithm, FA, is applied, due to its simplicity and relatively easy application. This algorithm was used without any modification, in other words, it was applied in its original form, as suggested by the author [2] [3].

The results of carrier optimization with two variables show that better results compared to the First Order Method (FOM), Subproblem Approximation Method, Graphical Method and ANSYS / Design are given by this biologically inspired algorithm. The set limit is completely satisfied. A significant advantage is that it is possible to visualize the flow of solution search, by forming a diagram for the scroll algorithm. Programs according to this algorithm were developed in MatLab.

The applied biologically inspired algorithms have proven to be effective in solving the optimization problem of carriers with two independent variables. Namely, from the attached results it can be seen that the obtained values of the goal function are better than the results of other methods, that the convergence is good and that the trap of entering the space of the local minimum is avoided.

\section{REFERENCES}

[1] F. Fedorik, Using optimization's algorithms by designing of structures, doctoral thesis, Institute of Structural Mechanics, Faculty of Civil Engineering Brno, University of Technology, (2013), 119-140.

[2] X.S. Yang, Firefly algorithms for multimodal optimization, Stoch. Algorithms: Found. Appl. (2009) 169-178.

[3] X., S., Yang, Firefly Algorithm, L'evy Flights and Global Optimization, Research and Development in Intelligent Systems XXVI (2010), pp 209-218. 
[4] https://www.solidworks.com/sw/images/content/Traini ng/SolidWorks_Simulation_Student_Guide-ENG.pdf, приступљено: јануар, $202 \overline{1}$

[5] G.Miodragović, P.Pravdić, S.Gavrilović, S. Pepić, M. Mojsilović, Primena biološki inspirisanih algoritama u rešavanju problema nelinearne optimizacije, ITOP 19 četvrta nacionalna konferencija sa međunarodnim učešćem, Čačak, april 2019, 203-210.

[6] Dassault Systemes, Introducing SolidWORKS, (C) 1995-2015, Dassault Systemes SolidWorks Corporation.

Pravin S. Game, Dr. Vinod Vaze, Dr. Emmanuel M, Bioinspired Optimization: metaheuristic algorithms for optimization, National Conference on Emerging Trends, Challenges and Opportunities in Data Mining and Information Security, NTCOMIS-2020.

\section{Optimizacija nosača primenom CAD softvera i biološki inspirisanih algoritama}

Marija Mojsilović ${ }^{*}$, Ivana Terzić ${ }^{2}$, Snežana Gavrilović ${ }^{3}$, Goran Miodragovićc ${ }^{4}$

Akademija strukovnih studija Šumadija - odsek Trstenik

$U$ ovom radu se prezentuje uporedna analiza primene biološki inspirisanix algoritma $i$ metodologije $u$ CAD programskim paketima, za utvrđivanje optimalnih vrednosti profila kod nosača sa dve nezavisne promenljive.

Kao primer, biološki inspirisanog algoritma za rešavanje ovog optimizacionog problema, primenjen je algoritam svica, dok je za primer $C A D-a$, uzet softverski paket SolidWorks.

Ključne reči: Metaheuristika, Nelinearna optimizacija, Biološki inspirisani algoritmi, Algoritam svica, CAE. 